\title{
Discursos da sensibilidade humana à causa animal
}

DOl: http://dx.doi.org/10.21165/el.v50i2.2911

\section{Manoel Sebastião Alves Filho'}

\section{Resumo}

Este artigo pretende apresentar desenvolvimentos preliminares de nosso doutorado, cuja proposta é a de analisar discursos da sensibilidade humana aos animais nos campos científico, jurídico e do terceiro setor, a fim de observar diferenças de constância e de intensidade na afirmação de que os animais são dotados de características como sensação, emoção, consciência e linguagem. Procuramos verificar a hipótese de que o reconhecimento da dor e da sensibilidade desses seres é mais constante e intenso do que o reconhecimento de suas capacidades cognitivas e linguísticas. Baseados na Análise do discurso derivada de M. Pêcheux e de M. Foucault, procuramos tecer algumas considerações acerca da sensibilidade humana aos animais no contemporâneo e realizar a análise de excertos de dois projetos de lei em defesa dos animais. Essas análises iniciais confirmam a nossa hipótese.

Palavras-chave: análise do discurso; história das sensibilidades; animais.

1 Universidade Federal de São Carlos (UFSCar), São Carlos, São Paulo, Brasil; manoel.filho2@hotmail.com; https://orcid.org/0000-0002-4798-7581 


\title{
Discourses of the human sensitivity to the animal cause
}

\begin{abstract}
This article intends to present preliminary developments of our doctorate, whose proposal is to analyze discourses of the human sensitivity to the animals in the scientific, legal, and third sector fields, to observe differences of constancy and intensity in the statement that animals are endowed with characteristics such as sensation, emotion, consciousness, and language. We tried to verify the hypothesis that the recognition of pain and sensitivity of these beings is more constant and intense than the recognition of their cognitive and linguistic abilities. Based on the Discourse Analysis derived from M. Pêcheux and M. Foucault, we seek to make some considerations about human sensitivity to the animals in the contemporary world and to analyze excerpts from two bills in defense of animals. These initial analyzes confirm our hypothesis.
\end{abstract}

Keywords: discourse analysis; history of sensibilities; animals.

\section{Introdução}

Em nosso mestrado, dedicamo-nos ao estudo do funcionamento discursivo do agronegócio no Brasil, a fim de compreender dizeres desse exitoso setor de comércio de carnes e seus derivados em uma sociedade paradoxalmente mais sensível à causa animal. No intuito de formularmos uma resposta satisfatória a essa questão, procuramos, em um primeiro momento, discursos a respeito da relação entre seres humanos e animais na história. Mais precisamente, o nosso interesse incidiu nas passagens em que o primeiro outorgou ao segundo propriedades como sensibilidade, emoção, consciência e linguagem ou insensibilidade, apatia e ignorância, com o intuito de determinar o seu estatuto e o seu direito ou não à vida. Partimos de unidades discursivas conhecidas, como certos campos do saber, cronônimos, autores e obras, mas à procura da identificação de enunciados e discursos mais essenciais, cujas força e alcance fazem com que ultrapassem esses domínios de saber, passem de um a outro autor, se expandam e transponham as fronteiras do tempo e do espaço, das eras e dos lugares. Esse sobrevoo histórico nos permitiu constatar a existência de pelo menos três concepções: a de que os animais são dotados de propriedades positivas e, por isso, os humanos podem comê-los desde que realizem certas práticas reverenciais; a de que eles têm atributos positivos e, por essa razão, os homens não devem comê-los; e a de que eles têm qualidades negativas e, em vista disso, podemos matá-los sem cerimônias.

Essa primeira investida, caracterizada pelo sobrevoo histórico de que falamos, nos revelou algumas informações interessantes. Ao analisar mitos e ritos de sociedades ditas primordiais, bem como livros de mitólogos que comparam essas narrativas com 
vestígios arqueológicos dos homens pré-históricos, constatamos a existência de pelo menos dois discursos. O primeiro enxerga certos animais como seres divinos, dotados de qualidades como consciência e linguagem, e com quem os homens constituíram um contrato baseado no seguinte termo: estes últimos apenas poderiam matar os primeiros e se alimentar de seus corpos se cumprissem certos rituais que garantiriam o retorno da alma animal para a natureza. O segundo, por sua vez, não mais enxerga os animais como descrito acima, mas na direção oposta: esses seres perdem o seu status divino, suas habilidades cognitivas e linguísticas, e são mortos sem a mesma reverência e cerimônia praticada pelos partidários da formação discursiva anterior.

A Antiguidade greco-latina também foi palco de dizeres e de ambivalências a esse respeito. Ao analisar livros de filósofos antigos, também encontramos pelo menos dois discursos contrastantes. O primeiro deles, encarnado, sobretudo, na figura de Pitágoras de Samos, enxerga os animais como seres dotados de alma, cuja deglutição pelos seres humanos está interditada. Essa posição é caudatária da doutrina da transmigração das almas, que prega que as almas vêm e vão deste mundo, assumindo diferentes formas a cada vez. Também prega o vegetarianismo e o cuidado com os animais, que podem ter almas antes humanas. O segundo, representado por Aristóteles, destitui essas criaturas de alma e de outras propriedades, em oposição ao animal racional, político e linguístico que é o homem cidadão ateniense.

A percepção personificada por Aristóteles perdurará pelo universo douto da Idade Média, e a imensa maioria dos teólogos católicos aliará ensinamentos bíblicos e aqueles legados pelos gentios gregos para manter rebaixado o estatuto dos animais e despojálos de qualidades eufóricas. Mas ainda aqui essa posição, embora hegemônica, não é total e definitiva. Eclesiásticos como São Francisco pregaram o amor pelos animais, e mesmo outros, como Gregório de Nissa, que reconheceram neles características como a capacidade de sentir. A população camponesa também parecia nutrir ambivalências em relação aos animais, ora os considerando criaturas brutas, ora invocando suas antigas qualidades, como a de terem alma. É o que nos mostra documentos inquisitoriais acerca do Sabá: o depoimento de muitos camponeses assinala a sua crença no poder mágico de certas criaturas do reino animal, lembrando elementos dos mitos e ritos que analisamos e da filosofia de Pitágoras de Samos.

A modernidade também é palco de refluxos e recrudescimentos na sensibilidade humana aos animais. René Descartes leva às últimas consequências a percepção religiosa dos bichos, descrevendo-os como meros autômatos despojados de qualquer propriedade positiva. Não sentem dor, não têm emoção, não têm inteligência: são máquinas a serviço do homem. Entretanto, o desenvolvimento de pesquisas científicas na área natural, em especial, as concentradas em Charles Darwin, devolve aos animais características como sensibilidade, emoção e inteligência. A filosofia e as humanidades também originaram exemplos nessa direção: Jean-Jacques Rousseau também reconhece sensibilidade nos 
animais, além de defender que os homens Ihes devem algum respeito por compartilharem da mesma condição de ser sensível.

Em nosso tempo, encontramos, em muitos lugares, discursos da sensibilidade humana à causa animal, que serão objeto de nossa discussão na terceira seção deste nosso artigo. Para citarmos, na introdução, apenas um exemplo, a filosofia ética dispensou todo um campo ao que ela chama de "especismo" e a quem ela também chama de "seres não humanos", atribuindo aos animais qualidades diversas como razões suficientes para que não os matemos e comamos. Essa sensibilidade, contudo, é contraposta pela existência da indústria agropecuária, cujo discurso produz sentidos que concebem as carnes e outros artigos de origem animal como mercadorias e alimentos, enquanto apaga outros dizeres que assinalam a condição animal desses produtos comercializados e o processo industrial pelo qual essas criaturas passam².

O primeiro olhar que dedicamos aos dizeres a respeito da sensibilidade humana à causa animal, apresentado de modo bastante sumário na página acima, nos mostrou sua abundância e relevância para o campo dos estudos discursivos, e sentimos a necessidade de melhor compreender a sua materialização em outras esferas da sociedade. Os campos científico, jurídico e do terceiro setor são fundamentais para o nosso propósito, uma vez que a constituição, a formulação e a circulação de discursos sobre o tema se processam ali de modo privilegiado. Este artigo pretende apresentar desenvolvimentos preliminares dessa nossa pesquisa, cuja proposta é a de analisar discursos da sensibilidade aos animais nesses três campos, a fim de observar diferenças de constância e de intensidade na afirmação de que eles são dotados de qualidades como sensação, emoção, consciência e linguagem. Procuramos verificar a hipótese de que o reconhecimento da dor e da sensibilidade desses seres é mais constante e intenso do que o reconhecimento de suas aptidões cognitivas e linguísticas.

Baseados na Análise do discurso de linha francesa derivada de Michel Pêcheux e de Michel Foucault, procuramos, neste artigo, tecer algumas considerações acerca do nosso tema e realizar a análise de excertos de dois projetos de lei em defesa da causa animal. 0 material de análise compreende o projeto de lei da câmara 27/2018, de autoria do deputado federal Ricardo Izar, e o projeto de lei do senado $n^{\circ} 470$, este último de autoria do senador Randolfe Rodrigues. Analisaremos o material mediante um método muito conhecido na Análise do discurso, a saber: a constituição de relações entre os enunciados de cada projeto, entre os dos dois projetos e entre eles e outros já-ditos do interdiscurso, focalizando os recursos linguísticos utilizados na formulação do texto do material. As análises desses dois projetos de lei confirmam a nossa hipótese de que o reconhecimento da dor e da capacidade sensitiva dos animais é mais constante e intenso do que o das outras duas aptidões.

2 Para saber mais sobre esse assunto, ver: Alves Filho (2020) e Piovezani e Alves Filho (2021). 


\section{Fundamentação teórico-metodológica}

Nossos pressupostos teóricos e procedimentos analíticos provêm da Análise do discurso de linha francesa derivada dos filósofos franceses Michel Pêcheux e Michel Foucault. Inicialmente, gostaríamos de apresentar uma concisa série de considerações sobre a noção de discurso em Foucault e sobre sua proposta de descrição arqueológica dos discursos, focalizando os postulados acerca do arquivo, da crítica do documento e das unidades discursivas. M. Foucault (1997) pensa os enunciados sob uma perspectiva que não é nem gramatical, nem lógica, mas histórica. Interessa-lhe investigar as condições de emergência dos discursos. Para ele, o discurso é a diferença entre tudo o que poderíamos dizer corretamente, segundo as regras da gramática e da lógica, e o que é efetivamente dito em uma determinada circunstância. Assim, o campo discursivo "é a lei dessa diferença" (FOUCAULT, 2010, p. 14).

Na produção dos dizeres há dispersão e heterogeneidade, mas há também a regularidade de práticas que regem o que pode ser dito. Ao postular a existência de uma ordem do discurso, ele supõe que "em toda sociedade a produção do discurso é ao mesmo tempo controlada, selecionada, organizada e redistribuída por certo número de procedimentos" (FOUCAULT, 2014, p. 8-9). Por essa razão, sabemos que "não se tem o direito de dizer tudo, que não se pode falar de tudo em qualquer circunstância, que qualquer um, enfim, não pode falar de qualquer coisa" (FOUCAULT, 2014, p. 8-9). O discurso é marcado pela raridade, pois é "o conjunto sempre finito e efetivamente limitado das únicas sequências linguísticas que tenham sido formuladas (FOUCAULT, 1997, p. 31). Ante a condição rara do discurso, cabe responder à questão de como algo pôde ser dito e não outra coisa em seu lugar.

Em conjunção com essa diferença forjada e gerida pela história, entre potência e rarefação, ocorre outra, que consiste na separação, no que foi dito, entre os textos e os enunciados que serão mais ou menos conservados e os esquecidos com maior facilidade. A reflexão sobre o controle do dizer e de suas diferentes durações está bem sintetizada na definição que M. Foucault (2010) consagra à noção de arquivo, que consiste em um conjunto de preceitos que, em uma época e sociedade determinadas, estabelecem os limites da dizibilidade, da conservação, da memória, da reativação e, finalmente, da apropriação. Na Arqueologia do saber, ele volta a definir o arquivo como "a lei do que pode ser dito, o sistema que rege o aparecimento dos enunciados como acontecimentos singulares" (FOUCAULT, 1997, p. 149).

No que se refere à crítica do documento, Foucault (1997) a identifica como uma contribuição da historiografia do seu tempo. Durante séculos, a história tradicional procedeu de modo a ordenar, a linearizar, a dar sentido a uma massa de acontecimentos heterogêneos. Ela partia de descontinuidades, mas em busca de fios condutores que as reunissem e as explicassem. A Nova História, por sua vez, passou a investigar os fatos do 
passado não mais olhando para cada micro acontecimento e procurando reuni-los todos em um conjunto para explicá-los, mas dedicando-se às lentas modificações históricas, às descontinuidades de longa duração. Por outro lado, a história das ideias, das ciências, da literatura e da filosofia deslocou a sua atenção das vastas unidades descritas como épocas ou séculos em busca de fenômenos de ruptura. Foucault (1997) dirá que estas duas últimas tendências inauguram outros modos de investigação histórica, outros modos de selecionar e organizar dados, de relacioná-los, não mais os inquirindo sobre se dizem a verdade, se nos dão pistas de uma linearidade oculta, mas trabalhando-os em seu próprio interior, em sua condição de acontecimentos singulares. Em uma palavra, esses movimentos passam a ver os documentos como monumentos.

Uma vez que a descrição arqueológica de Foucault (1997) consiste em analisar discursos, é preciso saber observar objetos empíricos e alcançar o objeto teórico. Textos e enunciados dispersos não são bem selecionados e inscritos em unidades discursivas com base em um suposto objeto comum. Também não são reunidos de modo satisfatório em grupos formados a partir do que foi dito sobre esse "mesmo" objeto em campos do saber previamente construídos ou ainda do que foi formulado pelos sujeitos que tematizaram esse objeto em enunciados. É o exame da ordem do discurso que nos permite melhor apreender as regularidades e as unidades do discurso. Em sua Arqueologia, Foucault (1997) defende que, para fazê-lo, é necessário suspender certos temas, noções e princípios que são geralmente mobilizados pelas ciências quando se tem de identificar e descrever a emergência histórica dos discursos. Esses temas, noções e princípios que devem ser suspensos são a "tradição" e a "influência", o "desenvolvimento" e a "evolução", a "mentalidade" e o "espírito da época", "o livro" e "a obra", e ainda a impossibilidade de "assinalar, na ordem do discurso, a irrupção de um acontecimento verdadeiro" (FOUCAULT, 1997, p. 28) e o princípio "segundo o qual todo discurso manifesto repousaria secretamente sobre um já-dito" (FOUCAULT, 1997, p. 28). Todos eles cumprem o papel equivocado de reagrupar a dispersão de acontecimentos discursivos diversos, no interior dos quais emergem o que importa: distintos referenciais, diferentes modalidades enunciativas, distintos domínios associados e diferentes materialidades. Ao proceder dessa maneira a esse reagrupamento, apagam-se as diferenças enunciativas e as singularidades dos acontecimentos.

Após essas considerações sobre postulados teóricos de M. Foucault, voltamo-nos para o trabalho realizado por M. Pêcheux. Aliando ao Materialismo Histórico saberes da Linguística e da Psicanálise, o conceito de discurso no pensamento de Pêcheux (1990) não corresponde ao caráter universal da língua para todos os falantes de uma comunidade linguística nem tampouco à condição individual da fala para cada um desses falantes; caracteriza-se, antes, pela normatividade de uma prática, determinada pela luta de classes. Assim, entre a universalidade de uma língua e a singularidade individual da fala estaria localizado um "nível intermediário, o nível da particularidade, que define 'contratos' linguísticos de tal ou tal região do sistema" (PÊCHEUX, 1990, p. 74, grifos do autor). Envolvendo relações de força e sentido, uma vez que se inscreve nos 
conflitos e contradições ideológicas e, ao mesmo tempo, nas remissões a outros dizeres, o discurso é concebido na AD proposta por ele e membros do seu grupo não como simples transmissão de informação, mas como "efeito de sentidos" entre interlocutores (PÊCHEUX, 1990, p. 82).

Com efeito, as relações de força materializam-se nas relações entre os dizeres de uma sociedade, por meio das ideologias. Estas também são concebidas em sua condição de "nível intermediário", pois "cada formação ideológica constitui assim um conjunto complexo que comporta atitudes e representações que não são nem 'individuais' nem 'universais', mas que se referem mais ou menos diretamente a 'posições de classe' em conflito umas com as outras" (PÊCHEUX, 2011, p. 72-73, grifos do autor). O discurso é entendido como uma das principais formas de materialização das ideologias, tendo em vista o fato de que:

As formações ideológicas comportam necessariamente, como um de seus componentes, uma ou várias formações discursivas interligadas, que determinam o que pode e deve ser dito [...] a partir de uma dada posição numa dada conjuntura. (PÊCHEUX, 2011, p. 73, grifos do autor).

Desse modo, ao materializar as ideologias, que, por seu turno, já são materializações dos conflitos de classe, o discurso determina o dizer e produz os sentidos:

O ponto essencial aqui é que não se trata somente da natureza das palavras, mas também e sobretudo das construções nas quais essas palavras se combinam, na medida em que essas construções determinam a significação que as palavras terão. [...] as palavras mudam de sentido segundo as posições sustentadas por aqueles que as empregam. [...] 'mudam de sentido' ao passar de uma formação discursiva para outra. (PÊCHEUX, 2011, p. 73, grifos do autor).

Em outro texto, Pêcheux falará do "caráter material do sentido" na abordagem discursiva oposto à "transparência da linguagem", que faz crer nas evidências da significação (1997a, p. 160-161). Retomando a reflexão anterior, o filósofo afırma que:

O sentido de uma palavra, de uma expressão, de uma proposição, etc., não existe 'em si mesmo' (isto é, em sua relação transparente com a literalidade do significante), mas, ao contrário, é determinado pelas posições ideológicas que estão em jogo no processo sócio-histórico no qual as palavras, expressões e proposições são produzidas (isto é, reproduzidas). Elas [...] recebem seu sentido da formação discursiva na qual são produzidas. (PÊCHEUX, 1997a, p. 160-161, grifos do autor). 
O nosso material de análise compreende o projeto de lei da câmara 27/2018, de autoria do deputado federal Ricardo Izar, e o projeto de lei do senado $n^{\circ} 470$, este último de autoria do senador Randolfe Rodrigues. Analisaremos o material mediante um método muito conhecido na Análise do discurso, a saber: a constituição de relações entre os enunciados de cada projeto, entre os dos dois projetos e entre eles e outros já-ditos do interdiscurso. Essas relações são feitas mediante a identificação e a montagem de cadeias parafrásticas, que se situam no interior das formações discursivas e que nos permitem depreendê-las. Serão ainda observadas as relações entre as distintas formações discursivas identificadas, que, por seu turno, estão articuladas a diferentes condições de produção do discurso e às posições de seus enunciadores. Pelo fato de as formações discursivas serem instâncias que determinam o que se diz e os modos de dizer, caracterizando-se como matrizes da produção do sentido, assim procedendo, será possível detectar, na dispersão dos discursos da sensibilidade humana à causa animal, as regularidades discursivas em que se materializam as relações de força e de sentido de nossa sociedade. Em suma, a polissemia constitutiva da linguagem é passível de ser interpretada a partir da detecção das paráfrases construídas pelo discurso em suas diversas condições de produção; trata-se, pois, de tomar os textos como unidades que possibilitam ao analista ter acesso ao próprio discurso, percorrendo, como nos ensina a linguista brasileira Eni Orlandi (1998, p. 60), "a via pela qual a ordem do discurso se materializa na estruturação do texto".

No intuito de atingir nossos objetivos, buscaremos ainda, sempre em uma perspectiva discursiva e em consonância com a metodologia parafrástica, analisar os recursos linguísticos usados na formulação dos textos do nosso material, como as preferências lexicais e os encadeamentos sintáticos, as modalidades enunciativas e as formas remissivas que constituem o referente textual. 0 encontro entre a retomada de já-ditos do interdiscurso e a aplicação desses referidos recursos na FD dos enunciados dos textos avaliados incide na produção de determinados efeitos e na construção das imagens e das relações entre interlocutores ${ }^{3}$.

\section{Discursos da sensibilidade humana à causa animal}

Em 21 de outubro de 2015, uma juíza argentina emitiu uma decisão judicial inédita em seu país: ela reconheceu uma orangotanga de propriedade do zoológico de Buenos Aires como um "sujeito de direito". Elena Liberatori, dirigente do Tribunal Contencioso, Administrativo e Tributário de número 4 da capital, deliberou uma disputa entre a Associação de Funcionários Públicos e Advogados pelos Direitos dos Animais e o Governo de Buenos Aires, responsável pelo parque. A primata, de nome Sandra, foi descrita pelos seus cuidadores como "solitária" e "cronicamente deprimida", o que motivou o advogado Andrés Gil Domínguez, representante da associação, a mover uma

3 Para saber mais sobre AD, ver: Orlandi (2012), Possenti (2011), Gregolin (2014), Piovezani (2020), Alves Filho e Piovezani (2020), além de Pêcheux (1990, 1997a, 1997b, 2011). 
ação judicial requerendo que ela deixasse de ser considerada uma "coisa" ou "objeto" para ser considerada uma "pessoa não humana" com direitos assegurados pela lei. 0 processo não produziu discussões somente no interior do judiciário, mas mobilizou diversos setores da sociedade. Para fundamentar a sua sentença, a juíza leu livros e conversou com juristas, sociólogos, etologistas, antropólogos e outros profissionais que pesquisam a vida animal. A polêmica reacendeu um intenso debate científico sobre a evolução darwiniana e os refluxos e recrudescimentos sobre as emoções nos animais, envolvendo especialistas de diversos países. Quando a possibilidade de enviá-la a algum parque ecológico estrangeiro foi cogitada, a magistrada reuniu uma equipe médica para aferir a sua saúde, condição para que ela fosse adotada. Enquanto a orangotanga realizava os exames, Liberatori não soltou a sua mão em nenhum momento. Para ela, cuja motivação jurídica é "defender inocentes, [...] não há nada mais inocente do que um animal" (GONZÁLEZ, 2019, p. 1). A despeito das tentativas do Ministério Público para reverter a decisão em tribunais de outras instâncias, Sandra foi aceita no Centro para Grandes Macacos da Flórida e será transportada pelo Estado argentino pelo preço de três milhões de pesos. Enquanto isso, o chefe do governo de Buenos Aires noticiou que o zoológico da cidade seria fechado para o público e transformado em um Ecoparque, autorizando o transporte dos demais animais para santuários e locais apropriados.

Não obstante sua presença constante e crescente atualmente, a sensibilidade dos seres humanos em relação aos animais não é exclusiva de nossa própria época e pode ser observada em outras ocasiões. Em A origem da desigualdade entre os homens, JeanJacques Rousseau (2019, p. 26) proclama que os deveres humanos "para com os outros não Ihe são unicamente ditados pelas tardias lições da sabedoria", mas também o são pelas qualidades que compartilham de acordo com a lei natural. A alteridade de que trata, todavia, não diz apenas respeito à espécie humana, mas compreende os animais. Estes, ainda que "desprovidos de luzes e de liberdade" (ROUSSEAU, 2019, p. 26), condição que os impossibilita de reconhecer essa lei, estão "ligados até certo ponto à nossa natureza pela sensibilidade de que são dotados" (ROUSSEAU, 2019, p. 26). Os animais:

Também devem participar do direito natural e que o homem está sujeito, em relação a eles, a acerta espécie de deveres. [...] De fato, parece que, se sou obrigado a não fazer nenhum mal a meu semelhante, é menos porque ele é um ser racional, do que porque é um ser sensível, qualidade que, sendo comum ao animal e ao homem, deve ao menos dar a um o direito de não ser maltratado inutilmente pelo outro. (ROUSSEAU, 2019, p. 26).

Essa percepção, ainda que crescente, não foi total e imediatamente incorporada por todos. Em 1850, cem anos após a ilustre resposta do filósofo à questão levantada pela Academia de Dijon, o general Jacques-Philippe Delmas de Grammont discursa na Assembleia Nacional em benefício dos animais. O deputado, sensibilizado pelo destino dos cavalos de guerra e pelos abusos humanos perpetrados contra toda sorte de bichos 
nas ruas de Paris, propõe um projeto de lei para punir todas as formas de violência contra eles, seja na via pública ou em casa. Diante de sua sugestão, seus pares não reagem de outra forma senão com risadas. A lei aprovada é muito menos vigorosa, criminalizando apenas o abuso público: uma decisão cujos efeitos protegem mais a sensibilidade dos espectadores do que a integridade dos animais agredidos. Os transgressores, aqueles que publicamente e indevidamente cometerem abusos contra animais domésticos, deverão ser punidos com o pagamento de uma multa de cinco a quinze francos e poderão ser presos de um a cinco dias (BARATAY, 2017).

Hoje, nós encontramos discursos da sensibilidade humana em relação aos animais com frequência. Eles estão presentes em publicidades do mercado de pets, cuja circulação não compreende apenas a televisão, mas outdoors em clínicas veterinárias e supermercados, além da distribuição de panfletos. A movimentação financeira do setor no país assinala a sua força sobre o brasileiro: terceiro maior do mundo, ele vem arrecadando uma média de vinte bilhões de reais por ano. Os animais domésticos, comumente cachorros e gatos, são retratados como seres sensíveis, emotivos, inteligentes, cuja saúde e bem-estar devem ser cultivados pelos seus donos através da compra de diversos produtos. Estes artigos, em resposta às necessidades cada vez mais exigentes dos animais, como uma alimentação equilibrada e nutritiva, banhos regulares com substâncias que não prejudiquem a pele e os pelos etc., são propagandeados como produzidos por profissionais excelentes, comprometidos com a pesquisa e trabalhando constantemente para proporcionar-Ihes uma vida melhor.

A produção de programas que retratam a vida selvagem também obteve uma expansão sensível nas últimas décadas. O Globo Repórter, por exemplo, vem dedicando matérias a respeito dos animais silvestres em horário nobre há anos, seguindo a tendência de redes de televisão de outros países. A British Broadcasting Corporation, pioneira neste tipo de programação, acumula em seu acervo dezenas de séries dedicadas inteiramente à vida animal na natureza. Narradas pela voz memorável de um dos maiores naturalistas do mundo, David Attenborough, elas receberam diferentes prêmios pela sua qualidade e pela perspectiva inédita da fauna planetária, além de somarem recordes de audiência de uma população telespectadora cada vez mais sensível ao conteúdo transmitido. A última delas, Planet Earth II, recebeu três estatuetas da British Academy of Film and Television Arts, a instituição de maior prestígio no que diz respeito à produção televisiva. Nelas, os telespectadores acompanham o cotidiano dos animais, sua luta pela sobrevivência, sua relação conjugal, seu amor pelos filhotes, enquanto o narrador descreve suas sensações, emoções e os riscos a que estão sujeitos pela ação humana sobre o mundo. Espécies como pinguins e cisnes, cujos casais continuam juntos durante toda a vida, são filmadas como uma constatação de que os animais também possuem sentimentos anteriormente avaliados como exclusivos do homem.

Em desenhos e filmes dedicados às crianças, os animais são antropomorfizados e vivenciam as adversidades da vida como um ser humano. Eles possuem características 
como sensibilidade, emoção, inteligência e linguagem. Os seus dramas envolvem situações de luto pela perda de parentes ou de aflição diante do desaparecimento de um filho ou de um amigo a quem se deve recuperar: longas como Procurando Nemo e 0 Rei Leão, este último relançado em live-action, são alguns exemplos. O discurso sobre a sensibilidade humana aos animais pode ser localizado até mesmo em adesivos afixados em automóveis, cuja diversidade de dizeres pode expressar amor a um animal, apoio a algum órgão de proteção dos mesmos ou advertência a outros motoristas para que tenham cuidado com eventuais bichos que cruzem as pistas desprevenidamente: encontramos enunciados como "Eu amo meu Border Collie", "Eu apoio iniciativas de proteção animal" e "Mantenha distância: eu freio para animais".

São os campos jurídico, científico e de organizações não governamentais que, porém, manifestam de forma mais sensível as disputas sociais acerca desse tema. Em âmbito internacional, duas declarações partidárias dos animais se destacam: a Declaração Universal dos Direitos dos Animais e a Declaração de Cambridge sobre a Consciência em Animais Humanos e Não Humanos. A primeira foi publicada pela ONU em parceria com ativistas e defensores da causa na década de setenta. O preâmbulo se destina a considerações a esse respeito: reconhece que todo animal possui direitos, confere responsabilidade aos seres humanos pelos crimes cometidos contra eles e institui deveres para resguardá-los de quaisquer formas de violência. Os artigos discutem as prerrogativas, condenando práticas desfavoráveis aos animais, como abandono, experimentos científicos, trabalho extenuante e apresentação em circos, além de reconhecerem a sua sensibilidade: embora não se contraponham ao comércio de alimentos, recomendam que o transporte e o abate animal sejam feitos sem provocar angústia, ansiedade ou dor (FELIPE, 2019).

Em 2012, na Francis Crick Memorial Conference on Consciousness in Human and nonHuman Animals, no Churchill College, da Universidade de Cambridge, a Declaração de Cambridge sobre a Consciência em Animais Humanos e Não Humanos foi redigida e assinada por eminentes cientistas da área neural. Entre os presentes estava o renomado físico britânico Stephen Hawking. O texto descreve resultados de estudos de especialistas e conclui com o seguinte:

Nós declaramos o seguinte: a ausência de um neocórtex não parece impedir um organismo de experienciar estados afetivos. Evidências convergentes indicam que animais não humanos têm os substratos neuroanatômicos, neuroquímicos e neurofisiológicos de estados de consciência, juntamente com a capacidade de exibir comportamentos intencionais. Consequentemente, o peso da evidência indica que os humanos não são os únicos a possuir os substratos neurológicos que geram a consciência. Animais não humanos, incluindo todos os mamíferos 
e pássaros e muitas outras criaturas, incluindo polvos, também possuem esses substratos neurológicos (LOW, 2012, p. 2, tradução nossa)4.

R. Dawkins (2018), célebre biólogo, em uma entrevista recente para o portal de notícias Big Think, discutiu a sensibilidade animal e se a crueldade que lhes é dispensada é uma nova forma de escravidão. Ele fundamenta os seus argumentos em biologia, em história e em ética: fala de nossa proximidade biológica com outros animais, nossas atitudes diante de outros períodos, como a escravização de seres humanos, e os nossos equívocos atuais em não reconhecer a dor dos animais, alimentando práticas que continuam a expôlos a situações de brutalidade e de morte. Efetivamente, a ciência abunda de dizeres e esse respeito. Naturalistas como Maturana e Varela (2001) discutem em seus livros sobre cognição humana e animal. Filósofos éticos como Singer (2010) e Felipe (2019) escrutinam o sofrimento imposto aos animais no interior das grandes indústrias do setor agropecuário.

As organizações não governamentais dedicadas à proteção animal também estão repletas desses discursos. Duas ONGs muito relevantes mundialmente são a Mercy For Animals e a World Animal Protection. A primeira dedica-se exclusivamente à preservação de animais explorados pela indústria agro. Seus ativistas produzem vídeos no interior de matadouros e expõem ao mundo o martírio a que são expostos os bichos destinados ao abate. Em seu site, somos informados de que a instituição existe para acabar com a maior causa de sofrimento no planeta: a exploração animal com fins alimentícios. Essas formas de produção alimentar, dizem eles, causam sofrimento ultrajante aos animais. $\mathrm{Na}$ aba "o problema", ficamos a par das práticas industriais, que sujeitam animais a rotinas abusivas e lhes infligem dor e sofrimento. $O$ site contém imagens de animais enjaulados que expressam sentimentos como medo.

A segunda possui uma extensão maior de atuação. Beneficiam-se de suas políticas de proteção animais de comunidades, de indústrias, selvagens e ainda aqueles vitimados por desastres, além de ela possuir um programa de educação global a respeito do tratamento que deve ser dispensado aos animais pelos seres humanos. Em seu site, somos informados de que os animais têm o direito de viverem livremente e sem dor. A maneira de cumprir esse desígnio, segundo a organização, é combater a crueldade e o sofrimento em todo o mundo. Ficamos a par, ainda, de sua atuação na redução de mortes de cachorros em Cali, na Colômbia, de seu apelo bem-sucedido aos países e às

4 No original: "We declare the following: The absence of a neocortex does not appear to preclude an organism from experiencing affective states. Convergent evidence indicates that non-human animals have the neuroanatomical, neurochemical, and neurophysiological substrates of conscious states along with the capacity to exhibit intentional behaviors. Consequently, the weight of evidence indicates that humans are not unique in possessing the neurological substrates that generate consciousness. Nonhuman animals, including all mammals and birds, and many other creatures, including octopuses, also possess these neurological substrates.". 
organizações internacionais para que valorizem a causa animal, de sua conscientização a respeito da importância do empenho individual dos seres humanos e da relevância dos animais para o bem-estar do todo o planeta 5 .

Finalmente, a legislação brasileira dispensou algumas alíneas para os animais e para a sua proteção. A Constituição Federal de 88 , em seu artigo de número 225, em que legisla a respeito do meio ambiente, prescreve que incube ao poder público o dever de proteger a flora e a fauna, e veda, na forma da lei, "as práticas que coloquem em risco sua função ecológica, provoquem a extinção de espécies ou submetam os animais à crueldade" (BRASIL, 1988, p. 131). A lei ambiental de número 9.605 sancionada em 12 de fevereiro de 1998 interdita "praticar ato de abuso, maus-tratos, ferir ou mutilar animais silvestres, domésticos ou domesticados, nativos ou exóticos" (BRASIL, 1998, p. 1), além de realizar "experiência dolorosa ou cruel em animal vivo, ainda que para fins didáticos e científicos [...] se existirem recursos alternativos". (BRASIL, 1998, p. 1). A pena para quem infringir a medida é a detenção de três meses a um ano, assim como o pagamento de multa a ser estabelecida pela justiça.

Em resposta à morte por espancamento de um cão nas dependências de uma rede de supermercados em dezembro de 2018, o senado federal aprovou um projeto de lei de autoria do senador Randolfe Rodrigues que aumenta a pena para os crimes de maustratos a animais em até quatro anos de detenção mais multa. Outro projeto, proposto pelo deputado Ricardo Izar, chegou a ser acrescido ao primeiro, mas depois foi separado e enviado para a Comissão do Meio Ambiente. Este, em tramitação, acrescenta dispositivo à Lei de número 9.605, de 12 de fevereiro de 1998, para dispor sobre a natureza jurídica dos animais não humanos. O projeto: "determina que os animais não humanos possuem natureza jurídica sui generis e são sujeitos de direitos despersonificados, dos quais devem gozar e obter tutela jurisdicional em caso de violação, vedado o seu tratamento como coisa" (BRASIL, 2013, p. 2).

Em nossa dissertação, conforme dissemos na introdução, estudamos discursos do agronegócio brasileiro, a fim de compreender o sucesso comercial e a receita bilionária desse setor econômico em uma sociedade paradoxalmente mais sensível à causa animal. O discurso da sensibilidade humana aos animais é a outra face desse paradoxo, face que nos propomos a estudar agora. Embora haja a constatação de que esse sentimento é mais forte em nossos dias do que em qualquer outra época, ele é um fenômeno contemporâneo cuja complexidade não foi devidamente analisada. É simplificadora a afirmação de que somos mais sensíveis sem uma pesquisa aprofundada do assunto. Ela não responde diversas questões. A distinção que se faz entre os animais, por exemplo. A sensibilidade não é a mesma para animais domésticos ou selvagens: a sociedade tende a proteger os

5 Para saber mais sobre as duas instituições, ver: https://mercyforanimals.org/ e https://www. worldanimalprotection.org/. 
primeiros, enquanto provoca o desaparecimento da flora e da fauna naturais, ainda que as ambiguidades que a constituem nos permitam encontrar cachorros abandonados e políticas públicas de proteção à onça pintada e outros seres vivos da mata brasileira. Entre estes últimos, há mais compaixão e mobilização de recursos pelos que estão ameaçados de extinção: um caso de preservação bem-sucedido sob um alto custo é o do panda gigante e outro em andamento é o do urso polar. Os campos industrial e econômico não possuem o mesmo grau de identificação a esse respeito do que o do terceiro setor: o estudo de discursos do agronegócio nos revelou o modo como os produtos e o lucro financeiro são evidenciados em detrimento do processo, apesar de a sua consolidação implicar a matança sistemática de bilhões de animais. Enfım, ela não é a mesma quando se trata de afırmar que eles possuem sensibilidade, emoção, consciência, linguagem etc. A análise desses discursos permitirá mais bem compreender as relações estabelecidas entre animais e seres humanos no mundo contemporâneo.

\section{Projetos de lei em defesa dos animais}

Com vistas a ilustrar nosso procedimento metodológico, efetuamos um breve exercício analítico a partir do art. 2 do projeto de lei da câmara 27/2018, de autoria do deputado federal R. Izar. Eis o excerto do documento:

Art. $2^{\circ}$ Constituem objetivos fundamentais desta Lei: I - afırmação dos direitos dos animais não humanos e sua proteção; II - construção de uma sociedade mais consciente e solidária; III - reconhecimento de que os animais não humanos possuem natureza biológica e emocional e são seres sencientes, passíveis de sofrimento. (BRASIL, 2013, p. 2).

Ao associarmos o polissêmico inciso "reconhecimento de que os animais não humanos possuem natureza biológica e emocional e são seres sencientes, passíveis de sofrimento" aos demais enunciados dessa sequência discursiva, às suas condições de produção e à posição de seu enunciador, constatamos sua condição de "forma-material" proveniente de um discurso no qual o reconhecimento de certas características dos animais e a afirmação dos seus direitos se contrapõem à sua inexistência ou à sua existência parcial e insuficiente na sociedade brasileira contemporânea. O projeto de lei se relaciona e tem seu sentido influenciado por discursos que lhe são contrários, que negam que os animais possuem essas propriedades e que dão ensejo a práticas de violência contra eles. Essa ambivalência atravessa todo o corpo social: os casos de crueldade contra os animais são abundantes, embora estejam acompanhados de denúncias e de uma midiatização crescente e constante. Recentemente, o assassinato do cachorro Manchinha por um segurança da rede de supermercados Carrefour produziu ampla repercussão na mídia e indignação de parte dos cidadãos, com respostas como boicote à rede e manifestações no estabelecimento. 
As unidades lexicais "reconhecimento" e "afirmação", esta última seguida da nominalização definida "dos direitos", ainda concorrem para a produção de um efeito de que as qualidades referidas são inerentes aos bichos, cabendo ao homem apenas identificá-las e garanti-las. A primeira é proveniente do discurso científico, de seus métodos e técnicas, que produzem esses dizeres. As ciências naturais têm sido categóricas na afirmação de que os animais são seres sensíveis. Ela está ligada a propriedades de natureza ética e legal que também se deve afırmar. Ambos os incisos indicam uma constatação e uma necessidade: é preciso enxergar o quejá está lá. Já o préconstruído "dos animais" produz, por sua vez, um efeito de evidência, de generalização e, com isso, o apagamento de diferenças que fazem com que sejamos mais sensíveis diante de alguns bichos e menos em relação a outros. Conforme mencionamos na seção anterior, não expressamos a mesma sensibilidade nem dispomos do mesmo esforço na proteção de animais domésticos e selvagens, de animais ameaçados ou não de extinção etc. Também não somos invariáveis quando se trata de comê-los, de utilizálos na execução de trabalhos fatigantes, de assistir-lhes em espetáculos circenses, de vê-los sofrer ou morrer em situações como vaquejadas, touradas etc.

Os dois incisos analisados acima estão relacionados à "construção de uma sociedade mais consciente e solidária". Esse enunciado materializa uma posição que alia justiça social e direitos dos animais, indicando que o processo de consciência e solidariedade coletiva ainda não atingiu resultados satisfatórios. O advérbio de intensidade "mais" assinala a obrigação de incluir ali os bichos. A polissemia dos adjetivos "consciente" e "solidário" também permite que identifiquemos outros sentidos. Há aqueles que são caudatários de uma posição em que a justiça social é exclusiva aos humanos, em especial, aos desfavorecidos, desprovidos de capital econômico. Entre eles, uns são favoráveis ao auxílio irrestrito dos que não têm como se manter, outros apenas de alguns; uns acham que isso deve ser feito via políticas públicas de estado, outros da iniciativa privada; uns acham que isso deve ser feito independentemente da situação, outros sob certas condições. Ao voltarmos a nossa atenção novamente ao inciso de número três, constatamos que o reconhecimento de que os animais possuem certas qualidades também elimina outras. Eles são dotados de emoção, sensibilidade e "senciência", mas não de linguagem. Mesmo o emprego de termos favoráveis produz esse efeito. Senciente é aquele que sente, que percebe pelos sentidos, que recebe impressões, propriedade que está abaixo da consciência, do raciocínio, da razão. Isso pode significar mais um motivo de reconhecimento da fragilidade dos animais diante dos homens ou a confirmação de sua inferioridade e menor importância social.

Os sentidos produzidos nesse excerto se alinham bastante bem àqueles construídos em outros textos do domínio jurídico que visam a proteger os animais, porque derivam do mesmo discurso. O senador R. Rodrigues, em seu próprio projeto de lei a favor da ampliação da pena de maus-tratos a animais, também se refere ao caráter sensível destes últimos. Na conclusão da justificativa, diz: "Desse modo, pretendemos aprimorar a proteção ao meio ambiente e aos animais contra as práticas abusivas que infligem dor 
e sofrimento absolutamente desnecessário à vida de seres indefesos que, quando bemcuidados, só nos rendem afeto, carinho e alegrias" (BRASIL, 2018, p. 4).

Ao relacionarmos os excertos entre si, encontramos semelhanças que evidenciam a sua vinculação. Por exemplo, o sintagma "que infligem dor e sofrimento" indica que os animais são seres sensíveis, como o faz o terceiro inciso do art. 2 do projeto de lei de R. Izar, quando declara que eles "possuem natureza biológica e emocional e são seres sencientes, passíveis de sofrimento". Entretanto, a despeito dessa correspondência, também identificamos diferenças entre eles. Enquanto o primeiro procura reconhecer e afirmar qualidades dos animais que são pouco ou de nenhuma forma reconhecidas e afırmadas, o segundo pretende "aprimorar" a sua proteção, o que sugere que já existem políticas a esse respeito na sociedade. Este último ainda inclui e dá evidência ao meio ambiente, preferência manifesta através da disposição sintática da formulação: ele precede animais, como um todo de onde derivam as partes. Finalmente, o cuidado com estes últimos está associado à produção de emoções humanas: eles "nos rendem afeto, carinho e alegrias". Há ainda muito a considerar, como as especificidades dos campos e dos gêneros discursivos. No caso das leis, o uso de verbos no infinitivo ou de substantivos que derivam deles; a objetividade e o caráter prescritivo, que restringem a possibilidade de outros dizeres; a pertença predominante ou exclusiva de unidades discursivas no interior do campo e aqueles que transcendem fronteiras etc. Em síntese, são esses os caminhos que pretendemos percorrer na análise dos textos em que se materializam a sensibilidade humana aos animais.

\section{Considerações finais}

Neste artigo, apresentamos desenvolvimentos preliminares de nossa pesquisa de doutorado, cuja proposta é a de analisar discursos da sensibilidade humana à causa animal nos campos científico, jurídico e do terceiro setor, a fim de observar diferenças de constância e de intensidade na afirmação de que os animais são dotados de propriedades como sensação, emoção, consciência e linguagem. Inicialmente, apresentamos de modo sumário alguns discursos sobre a relação entre homens e animais na história, mostrando diversas percepções acerca destes últimos. Após algumas considerações de ordem teórica e metodológica, apontamos a circulação de discursos da sensibilidade aos animais na sociedade contemporânea, em especial, no interior das instituições científica, jurídica e não governamental, assim como o que dizem e a maneira como esses enunciados são formulados. Finalmente, analisamos excertos de dois projetos de lei em defesa da causa animal. Em nossos dados, os animais são descritos como seres de direitos, dotados de características como sensação e emoção. Essa caracterização, entretanto, não implica o reconhecimento da condição pensante e até mesmo linguística dos animais. Também não equilibra a relação desigual entre as espécies, embora contribua para a diminuição desse desequilíbrio existente na sociedade. 


\section{Agradecimentos}

À Fundação de Amparo à Pesquisa do Estado de São Paulo - FAPESP [Processo nº 2019/17099-6] pelo financiamento desta pesquisa.

\section{REFERÊNCIAS}

ALVES FILHO, M. S. Homem, animal, indústria: uma análise discursiva do agronegócio brasileiro. 2020. Dissertação (Mestrado em Linguística) - Centro de Educação e Ciências Humanas, Universidade Federal de São Carlos, São Carlos, 2020.

ALVES FILHO, M. S.; PIOVEZANI, C. Homem, animal, indústria: uma análise de discursos publicitários do agronegócio brasileiro. In: SOARES, T. B. et al. (org.). Mídia, Linguagem e Sociedade: espaços, corpos e vozes na atualização da resistência. Campinas: Pontes Editores, 2020. p. 73-98.

BARATAY, É. S'émouvoir des animaux. In: CORBIN, A.; COURTINE, J-J.; VIGARELLO, G (org.). Histoire des Émotions. v. 3: de la fin du XIXe siècle à nos jours. Paris: Éditions du Seuil, 2017. p. 165-181.

BRASIL. Projeto de lei do senado n 470, de 2018. Brasília, 2018. Disponível em: https://legis. senado.leg.br/sdleg-getter/documento?dm=7892475\&ts=1559279463950\&disposition=inline. Acesso em: 28 set. 2020.

BRASIL. Projeto de lei da câmara n²7, de 2013. Brasília, 2013.

Disponível em: https://www.camara.leg.br/proposicoesWeb/prop_ mostrarintegra?codteor=1198509\&filename=PL-6799-2013. Acesso em: 28 set. 2020.

BRASIL. Lei no 9.605, de 12 de fevereiro de 1998. Brasília, 1998. Disponível em: http://www. planalto.gov.br/ccivil_03/leis/l9605.htm. Acesso em: 28 set. 2020.

BRASIL. Constituição da República Federativa do Brasil. Brasília: Centro Gráfico, 1988.

DAWKINS, R. Is animal cruelty the new slavery? Big Think, 01 de set. de 2018. Disponível em: https://bigthink.com/videos/richard-dawkins-is-animal-cruelty-the-new-slavery. Acesso em: 28 set. 2020.

FELIPE, S. Ética e experimentação animal. Florianópolis: Editora da UFSC, 2019.

FOUCAULT, M. A ordem do discurso. São Paulo: Edições Loyola, 2014. 
FOUCAULT, M. Resposta a uma questão. In: FOUCAULT, M. Ditos \& Escritos. v. VI. Rio de Janeiro: Forense Universitária, 2010.

FOUCAULT, M. Arqueologia do saber. Rio de Janeiro: Forense Universitária, 1997.

GONZÁLEZ, E. Sandra, a orangotango que se transformou em "pessoa". El país, 22 jun. de 2019. Seção Ciência. Disponível em: https://bit.ly/2SRw7Y8. Acesso em: 28 set. 2020.

GREGOLIN, M. R. Foucault e Pêcheux na análise do discurso: diálogos \& duelos. São Carlos: Claraluz, 2014.

LOW, P. The Cambridge Declaration on Consciousness. Francis Crick Memorial Conference. Cambridge, Reino Unido: 2012. Disponível em: http://fcmconference.org/ img/CambridgeDeclarationOnConsciousness.pdf. Acesso em 28 set. 2020.

MATURANA, H.; VARELA, F. A árvore do conhecimento. São Paulo: Palas Athena, 2001.

ORLANDI, E. Análise de discurso: Princípios \& procedimentos. Campinas: Pontes, 2012.

ORLANDI, E. Interpretação: autoria, leitura e efeitos do trabalho simbólico. Petrópolis: Vozes, 1998.

PÊCHEUX, M. Língua, linguagens, discurso: In: PIOVEZANI, C.; SARGENTINI, V. (org.). Legados de Michel Pêcheux. São Paulo: Contexto, 2011. p. 63-75.

PÊCHEUX, M. Semântica e discurso: uma crítica à afirmação do óbvio. Campinas: Editora da UNICAMP, 1997 .

PÊCHEUX, M. O discurso: estrutura ou acontecimento. Campinas: Pontes, 1997b.

PÊCHEUX, M. Análise automática do discurso. In: GADET, F.; HAK, T. (org.). Por uma análise automática do discurso: uma introdução à obra de Michel Pêcheux. Campinas: Editora da UNICAMP, 1990. p. 61-161.

PIOVEZANI, C. A voz do povo: uma longa história de discriminações. Petrópolis: Vozes, 2020.

PIOVEZANI, C.; ALVES FILHO, M. S. As relações entre animais e humanos: uma breve arqueologia de discursos. Revista Moara/Estudos Linguísticos, v. 57, n. 2, p. 162-180, jan./ jul. 2021. 
POSSENTI, S. Teoria do discurso: um caso de múltiplas rupturas. In: MUSSALIM, F; BENTES, A. C. (org.). Introdução à linguística. v. 3: fundamentos epistemológicos. São Paulo: Editora Cortez, 2011.

ROUSSEAU, J. J. A origem da desigualdade entre os homens. São Paulo: Cia das Letras, 2019.

SINGER, P. Libertação Animal. São Paulo: WMF Martins Fontes, 2010. 